CDD: 192

\title{
PHILOSOPHIA PRIMA COMO REPRAESENTATIO NA FILOSOFIA NATURAL DE HOBBES: EXAME DE FUNDAMENTOS METAFÍSICO-COGNITIVOS COMO COMPLEMENTOS TEÓRICOS DE SEU MATERIALISMO MECANICISTA
}

\author{
CLÁUDIO R. C. LEIVAS \\ Universidade Federal de Pelotas \\ Departamento de Filosofia \\ Rua Alberto Rosa, 154, $2^{\circ}$ andar \\ Centro, Pelotas, RS \\ CEP 96010-770 \\ BRASIL
}

clleivas@gmail.com

Received: 16.09.2010; Accepted: 0I.12.2010

\begin{abstract}
Resumo: O ponto de partida da Philosophia prima de Hobbes tem como referência a Física e a Metafísica de Aristóteles. O desenvolvimento posterior de sua Philosophia prima, porém, põe em marcha uma crítica da metafísica aristotélica que conduzirá a um remanejamento teórico de uma série de princípios e conceitos herdados da tradição. Considerada em seu conjunto, a filosofia primeira hobbesiana é constituída por uma definição ampla, isto é, a metafísica definida como ciência do ente enquanto ente (ao invés da clássica definição de ciência do ser enquanto ser), sobre a qual duas definições strictu sensu são erigidas: a metafísica como física geral - dizer o ente (ens) é dizer o corpo (corpus) e a metafísica como representação. Este paper é um esforço no sentido de compreender essas e outras questões concernentes aos estudos hobbesianos sobre a forma como conhecemos o mundo, as coisas e nós mesmos.
\end{abstract}

Palavras-chave: Metafísica. Representação. Física. Cognição. Óptica.

PHILOSOPHIA PRIMA AS REPRAESENTATIO IN

NATURAL PHILOSOPHY OF HOBBES: EXAM OF

METAPHYSICAL-COGNITIVE FOUNDATIONS AS

THEORETICAL COMPLEMENTS TO HIS

MECHANISTIC MATERIALISM

Manuscrito - Rev. Int. Fil., Campinas, v. 34, n. 2, p. 579-616, jul.-dez. 2011. 


\begin{abstract}
The starting point of Philosophia prima of Hobbes has as reference Physics and Metaphysics of Aristotle. The later development of his Philosophia prima, however, sets in motion a critique of Aristotelian metaphysics that will lead to a theoretical reorganization of a series of principles and concepts inherited from tradition. Considered as a whole, the first Hobbesian philosophy consists of a broad definition, that is metaphysics defined as the science of the entity as entity (instead of the classical definition of science of the being as being), on which are erected two strictu sensu definitions: metaphysics as general physics - to say the entity (ens) is to say the body (corpus) - and metaphysics as a representation. This paper is an effort to understand these and other questions related to studies Hobbesian on how we know the world, things and ourselves.
\end{abstract}

Keywords: Metaphysics. Representation. Physics. Cognition. Optics.

\title{
FILOSOFIA PRIMA ${ }^{1}$ COMO REPRAESENTATIO
}

\section{Delimitando o escopo da philosophia prima}

Por ocasião de uma obra recentemente descoberta na Bibliotèque Nationale de France (Paris) e que ficou conhecida como Crítica do De Mundo de Thomas White (Anti-White) ${ }^{2}$ foi possível constatar o ponto de partida tradicional ${ }^{3}$ das reflexões metafísicas de Hobbes bem como a subsequente reviravolta teórica em que ele elabora uma metafísica em conformidade com a estrutura geral de um sistema

\footnotetext{
${ }^{1}$ Hobbes prefere o termo philosophia prima (filosofia primeira) ao termo metafísica. Essa preferência indica duas coisas: — A predileção pelo latim, idioma usado na elaboração e tradução de muitas de suas obras mas, principalmente, a tentativa de efetuar uma depuração do uso inadequado do termo metà tà physikéa que, se originariamente significava simplesmente o que vem depois da física, com os escolásticos passa a significar coisas sobrenaturais e transcendentes à própria física, ou seja, uma espécie de trans-física.

${ }^{2}$ O texto original (em Latim) foi publicado pela primeira vez em 1973 por Jean Jacquot e Harold Whitmore (Livraria Vrin, Paris).

${ }^{3}$ Refiro-me aqui ao fato das reflexões metafísicas de Hobbes começarem (o que ficou evidente com a descoberta do De Mundo) com teses oriundas da metafísica de Aristóteles.
}

Manuscrito - Rev. Int. Fil., Campinas, v. 34, n. 2, p. 579-616, jul.-dez. 2011. 
filosófico cujas bases assentam na explicação mecânica de corpos em movimento. O ponto de partida da metafísica hobbesiana é apresentado no De Mundo da seguinte forma: "A primeira parte da filosofia, e a base de todas as outras partes, é a ciência em que os teoremas concernentes aos atributos do ser em geral são demonstrados, e essa ciência é chamada Pbilosopbia prima" (De Mundo, p. 23). Se perguntamos sobre o objeto de estudo dessa ciência, obtemos de Hobbes a seguinte resposta: "Ela portanto trata da essência, matéria, forma, quantidade, o finito, o infinito, qualidade, causa, efeito, movimento, espaço, tempo, [etc.],... e todas as outras noções que Aristóteles discute [em parte em sua física, em parte em sua metafísica]" (De Mundo, pp. 23 -24). A filosofia primeira ou metafísica segue aqui a definição aristotélica de ciência do ser em geral, isto é, ela é a "ciência do ser enquanto ser".

A substituição da ciência universal do ser por uma ciência universal do corpo dá as feições da Philosophia prima hobbesiana e isso ocorre mediante um procedimento que podemos chamar redução ôntica $\mathrm{e}$ que consiste no seguinte: dizer o ser (esse) é a mesma coisa que dizer o ente (ens) e dizer o ente é a mesma coisa que dizer o corpo (corpus): "O ens designa tudo o que ocupa um espaço, quer dizer que pode ser avaliado em comprimento, extensão e profundidade. A partir dessa definição, é claro que ens é a mesma coisa que corpus" (De Mundo, p. 312). Na concepção de Hobbes as coisas que existem, existiram ou existirão estão perfiladas sob o termo ens, enquanto sob o termo esse estão perfilados os modos segundo os quais são concebidos os seres nomeados de acidentes. A conversão do ser em acidente é especificada no De Mundo da seguinte forma:

\footnotetext{
"Resulta que o ser (esse) não é nada mais que o acidente do corpo (accidens corporis), pelo qual é determinado e distinguido o modo de conceber. É porque chamamos acidentes dos corpos, ser em movimento, ser em repouso, ser branco e outras coisas semelhantes que nós pensamos que elas são os corpos (inesse corporibus), porque são os diversos modos pelos quais nós concebemos os corpos" (De Mundo, XVII, pp. 312-313)
}

Manuscrito - Rev. Int. Fil., Campinas, v. 34, n. 2, p. 579-616, jul.-dez. 2011. 
Essa passagem da Critica do 'De Mundo' evidencia que já nos primeiros escritos de Hobbes havia a ideia da philosophia prima como metafísica do corpo tal qual encontraremos posteriormente desenvolvida no Leviathan e no De Corpore. Em Le vocabulaire de l'être dans la philosophie première [de Hobbes] M. Pécharman diz que "da mesma forma que a philosophia prima, segundo Hobbes, deve preferir dizer corpus, ao invés de ens, da mesma forma dirá accidens ao invés de esse" para significar o modo em que o corpo é determinado, visto que "o esse não tem estatuto senão relativamente a um corpo ou ente". ${ }^{4}$ De fato, temos em Hobbes uma conversibilidade de ente, corpo e matéria bem como uma conversibilidade de ser e acidente:

\footnotetext{
"O ente nesse sentido é tudo o que ocupa um espaço, quer dizer o que se pode estimar segundo a extensão, a largura e a profundidade. Parece que a partir dessa definição ens e corpus são a mesma coisa, pois todo mundo atribui igualmente a mesma definição ao corpo. Diremos portanto sempre corpus em lugar do ens do qual falamos" (De Mundo, XVII, p. 312/ pp. 310-311). ${ }^{5}$
}

Uma dupla determinação do ente como corpo e do ser como acidente permite medir essa reavaliação a qual Hobbes submete os conceitos da metafísica aristotélica. Diante disso, temos em Hobbes que a distinção entre ordo essendi e ordo cognoscendi é subsumida numa metafísica que reduz o ser, a essência e a substancia ao estudo do corpo em geral. A filosofia primeira hobbesiana é de agora em diante exclusivamente da ordem do conhecimento. Pécharman comenta essa questão da seguinte forma:

"A [tarefa da philosophia prima] é primeiro definir o nome mais comum de todos os entes (ens ou corpus), e o nome mais comum de todos os

\footnotetext{
${ }^{4}$ Pécharman (1992).

${ }^{5}$ Paginação referente ao original em latim.
} 
seus modos de ser (esse ou accidens). Contudo, enquanto o nome ens significa, como o nome simples corpus, um primeiro conceito, ao qual se acrescentam outros conceitos... o nome esse significa o fato mesmo da inerência de um acidente, qualquer que seja, a um corpo (...) o nome ens é positivo, pois nomeia um imaginabile, uma coisa que pode cair sob uma ideia; mas o esse pertence também à ordem do concebível, não enquanto ele seria uma coisa existente da qual eu possa ter um conceito, mas enquanto ele é o modo qualquer sob o qual toda coisa existente é concebida" (idem, pp. 34-35).

Dizer o ser como o fundamento último da realidade implica uma apreensão errônea e inadequada da própria realidade. O que chamamos real é composto por corpos em movimento. O que podemos saber a respeito dos corpos é da ordem do conhecimento e não da ordem da essência. ${ }^{6}$ Considerando que em Hobbes o termo corpo é definido como aquilo que existe de forma independente do pensamento, o que subsiste por si mesmo, surge imediatamente a seguinte indagação: como podemos conhecer a realidade corpórea das coisas que existem no mundo se não temos acesso cognitivo - direto ou intuitivo - aos próprios corpos? A fim de responder a essa questão Hobbes opta por uma solução radical. Ele resolve destruir o mundo (com todas as coisas corpóreas que existem dentro dele), com exceção de um único sobrevivente humano, que tem a responsabilidade de trabalhar cognitivamente sobre os escombros de um mundo que não existe mais a não ser em sua memória — onde jazem guardadas lembranças de imagens e pensamentos de antes da destruição. Essa estratégia argumentativa é conhecida como bipótese da aniquilação do mundo e se encontra inserida no início da segunda parte do De Corpore que é a parte reservada às suas reflexões metafísicas.

\footnotetext{
6 "A philosophia prima não considera o ser universal como tal, mas antes do que nossa concepção de ser corpóreo universal” (cf. Leijenhorst (2002, p. 38)).

Manuscrito - Rev. Int. Fil., Campinas, v. 34, n. 2, p. 579-616, jul.-dez. 2011.
} 


\section{A hipótese da aniquilação do mundo}

A filosofia primeira ou metafísica, conforme vimos antes, é uma parte do conhecimento filosófico que busca explicar os conceitos fundamentais da filosofia segunda ou física a partir do exame de seus princípios ou causas mediante definições. Consideremos que em Hobbes não há uma distinção entre definições nominais e definições reais, como encontramos em Aristóteles, isto é, "uma explicação do que pretendemos por um certo nome e uma explicação do que uma coisa 'é' realmente e essencialmente". ${ }^{7}$ Com efeito, as definições dizem respeito aos nomes das coisas, não às coisas em si mesmas. ${ }^{8}$ Podemos apenas descrever a natureza dos corpos externos, jamais apreender o que eles são realmente e essencialmente. Tanto é assim que na hipótese de o mundo deixar de existir o único sobrevivente humano desse apocalipse poderia ter ainda assim um conhecimento do mundo tal como ele era antes, pois teria guardado na memória ideias e representações do mundo tal como ele era realmente:

\footnotetext{
"Supondo-se a aniquilação de todas as coisas, alguém poderia perguntar o que permaneceria àquele homem [isto é, ao sobrevivente humano do apocalipse] como objeto de conhecimento filosófico, ou sobre o que raciocinar ou ao que dar nomes pelo uso do raciocínio. Eu respondo, portanto, que permaneceria àquele homem as ideias do mundo, de todos os corpos que ele tenha visto com seus olhos, ou percebido por qualquer outro sentido, quer dizer, a memória e a imaginação das grandezas, movimentos, sons, cores, etc. [Enfim,] todas aquelas coisas que, embora não sendo nada mais que ideias $\mathrm{e}$ fantasmas... são as coisas às quais ele daria nomes [e sobre elas construiria raciocínios]" (De Corpore, p. 92).
}

O resultado desse experimento é demarcar uma linha divisória entre a forma como podemos conhecer o mundo e o mundo como ele realmente é, entre o que é da ordem da imaginação e o que é da ordem

\footnotetext{
7 ibidem, p. 52.

8 idem.
}

Manuscrito - Rev. Int. Fil., Campinas, v. 34, n. 2, p. 579-616, jul.-dez. 2011. 
da realidade. Acima de tudo, mostrar que o referencial do conhecimento humano se encontra em nossa subjetividade, em nossas capacidades cognitivas, e não no caráter essencialista do real ou em sua objetividade externa:

"E muito embora, a uma certa distância, o próprio objeto real pareça
confundido com a aparência que produz em nós, mesmo assim o
objeto é uma coisa, e a imagem ou ilusão uma outra. De tal modo que
em todos os casos a sensação nada mais é do que a ilusão originária,
causada (como disse) pela pressão, isto é, pelo movimento das coisas
exteriores nos nossos olhos, ouvidos e outros órgãos a isso
determinados." (Leviatã, p. 16).

A existência do corpo é deduzida da representação. Em sentido estrito a filosofia primeira não pertence ao corpo como tal mas às nossas representações de corpos. O corpo de que se trata aqui é o corpo em geral, se quisermos, um corpo aparente desprovido de toda propriedade: cor amarela ou branca, figura triangular ou circular: $\mathrm{O}$ corpo que interessa à ciência do ens enquanto ens e que pode ser concebida como ciência do corpus enquanto corpus é o corpo como ens imaginabile (ente imaginário). Da constatação que o corpo aparente ocupa um espaço que não é o espaço ocupado pelo corpo real chegamos à definição de um espaço imaginário como a imagem ou a representação do corpo, isto é, "o espaço é o fantasma de uma coisa que existe fora de nossas mentes,... em que não consideramos nenhum outro acidente a não ser o fato do fantasma aparecer fora de nós" (De Corpore, p. 93).

O “espaço que nós imaginamos é imaginário em um duplo sentido: porque gerado por um ato de consciência e porque não corresponde diretamente ao espaço real". ${ }^{9}$ O tempo, por sua vez, é também imaginário. Um corpo, quando em movimento, deixa uma ideia de seu movimento na mente, isto é, uma sucessão contínua. Mas

${ }^{9}$ Brandt (1928, p. 253).

Manuscrito - Rev. Int. Fil., Campinas, v. 34, n. 2, p. 579-616, jul.-dez. 2011. 
como a mera ideia do movimento não é suficiente para nos dar a ideia de tempo, um antes e um depois do movimento deve ser também considerado, de forma que o tempo é então definido como "o fantasma do antes e do depois no movimento" (De Corpore, p. 94). Outros conceitos fundamentais além de espaço e tempo que são da competência da filosofia primeira são os seguintes: corpo e acidente, causa e efeito, poder e ato, identidade e diferença.

\section{Filosofia primeira como representação}

No Curto Tratado dos primeiros principios (1630-1631) — obra atualmente considerada por muitos como a primeira obra filosófica de Hobbes - Hobbes escreve que "como os objetos são um, por união ou reunião, assim são os fantasmas que os representam (Phantasmata that represent them), pois não são senão seus reflexos" (CTr. III, p. 43). Observe-se que nesse primeiro escrito de Hobbes — que J. Bernhardt deu o subtítulo na tradução para o francês de "O nascimento de Thomas Hobbes para o pensamento moderno" — o conceito de representação já está presente e se encontra ali associado às noções de "fantasma ou aparição" (Phantasma or Apparition). O termo phantasma e o termo repraesentatio fazem parte do vocabulário do aparecer ${ }^{10}$ de Hobbes pelo simples fato que na visão de Hobbes denominamos fenômeno todas as coisas que aparecem (De Corpore, XXV, p. 298). Fantasma e representação devem por esse singular motivo ser concebidos na ordem da subjetividade fenomênica. Hobbes escreve mesmo no De Corpore que de todos os fenômenos "o mais admirável é a própria aparição" (idem). O ato mesmo do aparecimento das coisas é mais formidável do que aquilo que aparece.

O que aparece tem o seu aparecer assinalado por intermédio das sensações. O aparecer, isto é, a consciência da exterioridade, ${ }^{11}$ por que

\footnotetext{
10 Zarka (1992b, p. 17).

11 idem.
}

Manuscrito - Rev. Int. Fil., Campinas, v. 34, n. 2, p. 579-616, jul.-dez. 2011. 
principia na sensação, está contudo sempre sujeito ao engano das sensações. $\mathrm{Na}$ ordem do conhecimento sensível ter consciência do mundo exterior não significa de nenhuma forma ter consciência dos enganos ou ilusões que fazem parte de nossa sensibilidade. Lembremos por ora que Hobbes nos diz nos Elementos da Lei que, no que concerne aos enganos da sensação, somente a própria sensação pode empreender algum tipo de reparo ou correção: "Acidentes ou qualidades que nossos sentidos nos fazem pensar que existam no mundo, não estão lá, constituindo apenas aparências e aparições ... e este é o maior engano da sensação, que também deve ser corrigido pela sensação" (El. Lei, I, p. 56). É importante pois que possamos distinguir — a titulo de análise, pois tudo ocorre num mesmo instante — a causa fisiológica da representação (que se encontra em nossa sensibilidade) da representação como aparição ou fantasma. Sobre essa questão Zarka sugere o seguinte:

\footnotetext{
"Lembremos simplesmente... que a representação resulta, para o ser sensível, de um movimento fisiológico centrifugo, provocado pelo movimento do objeto sobre os sentidos. As qualidades sensíveis são pois subjetivas, elas dependem de uma modificação interna do sujeito. [Contudo ...] em sua estrutura a representação é uma aparição sempre extática: o que aparece parece fora de nós, de tal forma que não parece depender do poder do espírito. Esse caráter extático da representação é o que faz dela uma representação". ${ }^{12}$
}

A philosophia prima como repraesentatio se ocupará dessa forma com os fantasmas ou aparições, isto é, com os fenômenos que aparecem como que externos a nós, onde a dimensão do aparecer é priorizada em relação à dimensão do corpo. $O$ começo dos estudos sobre metafísica no De Corpore é assinalado pelo ato de representar as coisas como se elas tivessem subitamente desaparecido junto com a realidade constitutiva do mundo externo. Ao sobrevivente da conjetura do fim do mundo contudo as coisas aparecem como sendo a realidade

12 Zarka (1992b, p. 26).

Manuscrito - Rev. Int. Fil., Campinas, v. 34, n. 2, p. 579-616, jul.-dez. 2011. 
externa não obstante elas sejam de fato a representação que resulta de uma realidade estrategicamente deixada em suspensão, de forma que "idéias e fantasmas, acidentes internos daquele que imagina, aparecerão como exteriores e como independentes do poder do espírito" (De Corpore, VII, p. 93).

O processo de suspensão da realidade — se me permitem a expressão - operado mediante uma ficção da mente é um recurso usado por Hobbes para operar a transformação da metafísica do corpo em metafísica do fenômeno ou representação. Adverte-se que o correlato empírico e objetivo estabelecido pela física corpuscular de Hobbes sempre estará presente como causa de toda experiência cognitiva humana. O recurso da ficção do fim do mundo permite porém que a ordo cognoscendi suprima a ordo essendi e coloque em seu lugar o mundo da pura subjetividade composto por fantasmas e representações. Hobbes pode então dizer que "muito embora... o próprio objeto real pareça confundido com a aparência que produz em nós, mesmo assim o objeto é uma coisa, e a imagem ou ilusão uma outra" (Leviatã., p. 10). Nos Elementos da lei Hobbes esclarece a distinção entre a representação e a própria coisa: "Essas imagens mentais e representações (representations) das qualidades das coisas fora de nós, são o que chamamos cognição, imaginação, ideias, informação, concepção, ou conhecimento delas" (El. Lei., I, p. 48).

Observe-se que a essa passagem dos Elementos da Lei onde Hobbes se refere à noção de representação precede uma passagem onde a reflexão da hipótese da aniquilação do mundo é apresentada de forma semelhante ao De Corpore. A philosophia prima de Hobbes, mutatis mutandis, tem a ver doravante com a separação da representação e da coisa e, a partir dessa separação, é estabelecido o conteúdo das nossas representações. A categoria do aparecer - o mais admirável dos fenômenos - é o elemento norteador desse conteúdo: nosso campo mental é preenchido por ideias e fantasmas que são percebidos por nós 
ou como acidentes internos da mente ou como apariçôes de coisas externas que parecem existir fora de nós:

\begin{abstract}
"Pode-se considerar [ideias e fantasmas] de duas maneiras: como acidentes internos da mente, como se considera quando se trata das faculdades da mente, ou como aparições das coisas externas, concebidas não como existentes mas como parecendo existir ou estar fora de nós" (De Corpore, VII, p. 94).
\end{abstract}

Sobre essa questão Zarka escreve que é menos de uma realidade que de uma irrealidade da imagem que é preciso falar ao se considerar a representatividade da representação em Hobbes, pois "a representação não é senão um ser imaginário ou fingido e como tal se opõe à coisa ou ao ente". ${ }^{13}$ De fato, na compreensão de Hobbes a representação como aparição ou fantasma implica que as imagens que parecem estar fora de nós sejam da ordem da ficção, o que implica a ausência de corpo ou ente: "É uma mera ficção e é não-ente (not ens), mas as próprias ficções existem dentro de nós" (De Mundo, III, p. 42). A metafísica do fenômeno suspende assim a metafísica do corpo quando se trata de evidenciar o caráter representativo da imagem. A suspensão do corpus ou do ens significa a suspensão da realidade. Essa é a função da hiperbólica hipótese da destruição do universo: mostrar que é uma ilusão pensar - como pensava Aristóteles, por exemplo — que as coisas determinam a forma de nosso aparato cognitivo.

$\mathrm{O}$ que existe são simplesmente nossos fantasmas e representações. Se pensarmos de nossas representações como reflexo especular da realidade externa isso se deve a um engano da sensação que pode ser compreendido da seguinte forma: "Assim como a sensação me diz, quando vejo diretamente um objeto, que a cor parece estar no objeto, assim também a sensação me diz, quando vejo por reflexão um objeto, que a cor não está nele" (El. Lei., I, p. 48). Podemos constatar a partir dessa passagem que Hobbes usa como recurso a linguagem óptica

13 Zarka (1987, pp. 53-54).

Manuscrito - Rev. Int. Fil., Campinas, v. 34, n. 2, p. 579-616, jul.-dez. 2011. 
para explicar a forma ilusória como percebemos a realidade. O que ele diz a seguir nessa mesma obra — isto é, nos Elementos da Lei - sobre a questão da separação entre o mundo subjetivo do fenômeno e o mundo objetivo das coisas nos parece particularmente esclarecedor e digno de nota:

\footnotetext{
"Por isso, segue-se também que quaisquer acidentes ou qualidades que os nossos sentidos nos fazem pensar que existam no mundo, não estão lá, constituindo apenas aparências e aparições. As coisas que realmente estão no mundo, fora de nós, são os movimentos que causam essas aparências" (Elementos da Lei, I, p. 48).
}

É contudo fundamental compreendermos que a sensação não é parte constitutiva da philosophia prima. É importante bem assinalarmos isso para não confundirmos a natureza da representação como aparição com a natureza da representação sensivel - como não podemos confundir, de forma análoga, a imagem de uma coisa com a própria coisa.

\section{AS REPRESENTAÇÕES COGNITIVAS}

Concepções e pensamentos são representações no modo de compreender de Hobbes. Considerados isoladamente ou desencadeados — isto é, não articulados como elos amarrados e justapostos numa rede ou cadeia de pensamentos — cada pensamento ou concepção em particular "é uma representação ou aparência" (Lev., cap. 1, p. 9) dos objetos externos. O modo de acesso ao conhecimento da realidade externa é inicialmente representacional: "Estas imagens mentais e representações das qualidades das coisas fora de nós, são o que chamamos cognição, imaginação, ideias, informação, concepção, ou conhecimento delas. E a faculdade, ou poder, pelo qual somos capazes desse conhecimento, é o que aqui denomino por poder cognitivo ou conceptual" (Elem., cap. 1, p. 48).

As representações cognitivas podem apresentar-se de diferentes formas conforme o tipo de "faculdade da mente" (Elem., cap.1, p. 48) escolhido para entrar em contato com o objeto externo. Como tudo

Manuscrito - Rev. Int. Fil., Campinas, v. 34, n. 2, p. 579-616, jul.-dez. 2011. 
começa na sensação, a própria sensibilidade é definida inicialmente como um tipo de representação originária. A representação cognitiva, nesse caso, é denominada representação sensivel. Esse tipo de representação depende da presença do objeto. Constatada a ausência do objeto e o consequente enfraquecimento ou obscurecimento de sua imagem chamamos então a representação cognitiva de representação imaginativa. A diferença entre essas duas versões oriundas das representações cognitivas é assinalada por Hobbes a seguir: "Uma concepção obscura é aquela que representa todo o objeto em conjunto... e quanto mais ou menos partes forem representadas, assim se diz que a concepção ou representação é mais ou menos clara. Considerando então a concepção que, quando produzida pela sensação era clara e representava distintamente as partes do objeto, e quando nos vem novamente é obscura, achamos que nela falta algo que esperávamos e, por isso, a julgamos passada e enfraquecida" (Elem., cap. 3, p. 62).

\section{As Representações Sensíveis}

(a) Da natureza das representações sensiveis

O conhecimento sensível assinala o princípio da vida cognitiva dos seres vivos. Através da sensação o mundo externo é primeiramente percebido como objeto de conhecimento. Porém, como o acesso cognitivo à realidade externa é indireto, a natureza dotou os seres vivos de um medium para extrair as informações dos objetos que pressionam os diversos órgãos sensoriais. Essa estrutura mediúnica é a própria sensação metamorfoseada como fantasma ou representação:

\footnotetext{
"A sensação é um fantasma, feito pela reação e esforço para fora no órgão da sensação, causado por um esforço para dentro a partir do objeto, permanecendo ali por algum tempo" (De Corpore., XXV, p. 391).
}

Manuscrito - Rev. Int. Fil., Campinas, v. 34, n. 2, p. 579-616, jul.-dez. 2011. 
No Curto tratado dos primeiros principios Hobbes se refere a uma sutil equivalência entre phantasma e repraesentatio: — "Como os objetos são um, por união ou reunião, assim são os fantasmas que os representam" (CT., p. 42). Enfim, nas primeiras linhas do primeiro capítulo do Leviatã Hobbes enfatiza que considerados não por união ou reunidos em cadeia, mas isoladamente, cada pensamento do indivíduo humano perceptivo "é uma representação ou aparência de alguma qualidade, ou outro acidente de um corpo exterior a nós, o que comumente se chama um objeto" (Leviatã., I, 1, p. 15). A sensação tem pois uma função representacional em Hobbes. $O$ início das representacõos sensiveis se assenta naquilo que na visão de Hobbes é o acontecimento mais admirável de toda a vida cognitiva das criaturas sensíveis, isto é, o próprio aparecer:

"De todos os fenômenos ou aparências que existem próximos de nós, o mais admirável é a própria aparição (to phainesthaı); ou seja, que alguns corpos naturais têm neles mesmos as estruturas [ou modelos (patterns)] de quase todas as coisas e outros de nenhuma. De forma que se os fenômenos ou aparências são os princípios pelos quais nós conhecemos todas as outras coisas, devemos necessariamente reconhecer a sensação como o princípio pelo qual conhecemos aqueles princípios, e que todo conhecimento que temos é dela originário" (De Corpore., XXV, p.389).

Consideremos, antes de tudo, que os termos fenômeno, aparência, fantasma e imagem são termos equivalentes em Hobbes, pois de acordo com o que ele diz no De Mundo, "[em meu esquema] um e o mesmo movimento da mente tem agora recebido quatro [diferentes] nomes para quatro diferentes pontos de vista ...: Esses nomes são: phantasma, imago, imaginatio e memoria" (De Mundo., XXX, 7, p. 367). Podemos dizer, porém, que as representações cognitivas - sejam elas sensíveis, imaginativas ou visuais — são definidas por Hobbes meramente como tipos distintos de efeitos causados por um mesmo movimento que ocorre no 
interior de nossas vidas mentais? São as representações cognitivas simples efeitos desses movimentos internos operados mentalmente? Em suas reflexões sobre philosophia prima no capítulo VII do De Corpore Hobbes esclarece essa questão ao estabelecer uma divisão fundamental quanto a forma como conhecemos as coisas. Ele diz ali que as quais podem ser conhecidas ou (1) como acidentes internos da mente ou ainda (2) como não existindo realmente, mas simplesmente parecendo existir.

\begin{abstract}
"Consequentemente as coisas podem ser consideradas... ou como acidentes internos de nossa mente, de tal modo que as consideramos quando a questão é sobre alguma faculdade da mente; ou como espécies (species) das coisas externas, não como existindo realmente, mas apenas como parecendo existir, ou [parecendo] ter uma existência (being) fora de nós" (De Corpore., VII, 1, p. 94).
\end{abstract}

A sensação aparente de exterioridade ou simplesmente consciência de exterioridade determina as representações cognitivas. Nos Elementos da Lei Hobbes diz que as "representações das qualidades das coisas fora de nós são o que chamamos cognição" (Elem., cap. 1, p. 48). A representação cognitiva é pois a capacidade de conhecer as qualidades sensíveis dos objetos conforme esses aparecem para nós e parecem fora de nós. Objetos que se reapresentam (isto é, apresentam-se novamente) em nós e para nós, originando, a partir disso, fenômenos distintos, aparecem na forma de fantasmas ou representações, isto é, como aparições das coisas exteriores, de forma que o que é próprio da representação é o "apresentar ou representar alguma coisa sem ser ela mesma uma coisa, quer dizer, sem receber o estatuto de uma realidade". ${ }^{14}$ Hobbes acredita que a forma como representamos as coisas é tão forte e intensa que mesmo na configuração apocalíptica da hipótese da destruição do mundo externo continuaríamos a acreditar nas imagens representadas das coisas

14 Zarka (1992b, p. 18).

Manuscrito - Rev. Int. Fil., Campinas, v. 34, n. 2, p. 579-616, jul.-dez. 2011. 
armazenadas no interior de nosso cérebro antes do the day after como algo indubitavelmente externo e independente da mente:

\begin{abstract}
"A esse homem [isto é, o único sobrevivente do apocalipse] ficariam as idéias do mundo e de todos os corpos que havia contemplado com seus olhos antes da aniquilação ... tudo o qual, ainda que não fosse mais que idéias e fantasmas que estariam presentes internamente somente a quem as imaginasse, aparecer-lhe-iam porém como externas e não dependentes da mente" (De Corpore., VII, p.).
\end{abstract}

O estatuto representacional da sensação, mutatis mutandis, vem a ser possível, em primeiro lugar, porque a sensação é dotada de uma memória de curtíssima duração, porém suficiente para gerar uma sensação aparente de exterioridade que permite a percepção do percebido:

\footnotetext{
"Não podemos começar nossa busca por tais princípios [isto é, a busca de nossas representações da realidade externa] por outro fenômeno que a própria sensação, ... [ou seja,] pela memória que por algum tempo permanece em nós das coisas sensíveis, ... pois aquele que percebe que tem percebido, lembra" (De Corpore., XXV, p.389).
}

A correlação entre sensação e representação é assegurada, em segundo lugar, pela capacidade de mudança, que resulta da forma diversa como os fantasmas são representados, por exemplo, quando o objeto da percepção é alterado e novos fantasmas tomam o lugar dos primeiros. Essa capacidade de mudança, aqui associada com as representações sensíveis, é identificada por Hobbes como sendo o conatus, isto é, um tipo de movimento interno plenamente compatível com a sensação. Tal compatibilidade parece justificada pelo fato que a sensação é ela própria um tipo de movimento — além de ser, como foi dito antes, a sede central das representações ou fantasmas intermitentes que aparecem continuamente em nossa vida mental. Veremos a seguir que é através da capacidade da mudança que se abre um campo cognitivo bastante extenso e complexo em que o princípio de comparação e diferença atua como uma espécie de chef d'équipe ou coordenador geral. 


\section{(b) Comparação, Diferença e Representação}

O princípio de comparação e diferença é fundamental para que as representacões enquanto fantasmas surjam nos órgãos sensíveis das criaturas vivas. De fato, "não se pode falar de sensação se não há comparação e distinção de fantasmas". ${ }^{15}$ A aparição dessas entidades fenomênicas chamadas fantasmas (entidades essas que surgem por reação sensível uma vez provocadas pela presença de um objeto epistêmico qualquer) é engendrada por um processo de discriminação ou separação operado pelo princípio de comparação e diferença:

\footnotetext{
"Por sensação compreendemos comumente o juízo que fazemos dos objetos por seus fantasmas; a saber, ao comparar e distinguir aqueles fantasmas... de forma que a sensação tem necessariamente alguma memória aderente a ela, pela qual os primeiros e os últimos fantasmas podem ser comparados juntos, e diferenciados uns dos outros" (De Corpore., XXV, p. 393).
}

A seletividade e a diversidade são dois aspectos inerentes à sensação, sem os quais não haveria conhecimento sensível e, consequentemente, não existiriam o que conhecemos como representações cognitivas. Na hipótese contra factual de podermos representar apenas um único fantasma isso ocasionaria uma suspensão da sensação, pois "sentir sempre o mesmo e não sentir vem a ser o mesmo" (De Corpore., XXV, p. 394). O princípio de comparação e diferença, dessa forma, atua de modo a fazer com que a multiplicidade de fantasmas gerados no centro nervoso da vida cognitiva de indivíduos sensíveis seja submetida ao discernimento e percepção de diferenças justapostas no plano de uma ordem de prioridades. A seleção e a discriminação de fantasmas, por outro lado, influem decisivamente na intensidade daquela memória que é própria da sensibilidade animal. Aliás, uma das

15 Zarka (1992b, p. 18).

Manuscrito - Rev. Int. Fil., Campinas, v. 34, n. 2, p. 579-616, jul.-dez. 2011. 
diferenças fundamentais dos vegetais em relação aos animais é que os primeiros não possuem órgãos que funcionem plenamente como retentores mnemônicos da multiplicidade de fantasmas gerados na sensação:

\footnotetext{
"Embora pela reação dos corpos inanimados um fantasma possa ser feito, cessaria, contudo, tão logo o objeto fosse removido. Pois a menos que esses corpos tenham órgãos, como as criaturas vivas os têm, adequados para reter tais movimentos, sua sensação seria tal que eles nunca se lembrariam" (De Corpore., IV, pp. 300-301).
}

Conforme pudemos perceber até aqui, a sensação deve ter em si mesma uma variedade contínua de fantasmas para que esses possam ser discernidos uns dos outros e que da mesma forma que sem sensação não há memória sem memória não há retenção de fantasmas, e, por conseguinte, nada para ser discernido ou diferenciado comparativamente. É de se indagar no momento se essa multiplicidade fenomênica, enquanto submetida àquele princípio fundamental que orienta a comparação e a distinção de fantasmas (isto é, o princípio de comparação e diferença) é algo que se dá num só tempo ou em tempos distintos. Hobbes diz que a natureza da sensação é tal que a comparação e a diferenciação dessas entidades fenomênicas chamadas fantasmas ocorre uma de cada vez, de forma que dois objetos registrados nos órgãos sensoriais não produzem dois fantasmas distintos, mas um só resultante da composição de ambos. Por exemplo, quando abrimos a página de um livro, percebemos visualmente uma página inteira, sem que isso nos dê acesso ao seu conteúdo: somente ao lermos cada palavra, uma de cada vez, podemos com isso fazer associações, comparando umas com as outras, o que nos permitirá enfim emitir um juízo sobre o conjunto das informações extraídas. Tudo isso requer, obviamente, a representação das partes num espaço e tempo determinados. Com efeito, nossas representações sensíveis, concebidas como sensações aparentes de exterioridade ou consciências de exterioridade, não podem estar separadas da percepção do espaço e da consciência do tempo. 


\section{(c) Do Objeto da Representação}

O objeto que é próprio da representação é formado por um engano da sensação que ao considerar um acidente interno da mente como sendo algo externo e objetivo fixa os limites das aparências perceptivas como se fossem os limites de entidades reais. Objeto real, no vocabulário de Hobbes, é tudo aquilo que constitui o mundo exterior e pode ser concebido como independente de estruturas mentais. Numa acepção mais ampla, objetos reais são corpos materiais que subsistem por si próprios independentes do pensamento humano e que ocupam algum espaço. ${ }^{16}$ (Veremos depois que na compreensão de Hobbes considerar um corpo como possuidor de uma certa substancialidade imaterial é uma contradictio in adiecto, isto é, uma contradição nos termos.) A percepção ou apreensão da multiplicidade de objetos ou coisas que constituem a realidade exterior depende da forma como as capacidades sensório-perceptivas de uma criatura sensível são estimuladas pelos movimentos externos constitutivos desses mesmos objetos ou coisas. O objeto real se metamorfoseia num objeto aparente, isto é, num objeto representacional, quando por seu movimento pressiona um determinado órgão sensorial originando ali, como resultado de sua força centrípeta, um movimento ou conatus interior que, devido a sua natureza reativa ou centrífuga, é então fisiologicamente pressionado para fora, cujo efeito no indivíduo senciente é aquilo que denominamos anteriormente sensação aparente de exterioridade:

"A causa da sensação é o corpo exterior, ou objeto, que pressiona o órgão próprio de cada sentido... a qual pressão, pela mediação dos nervos e outras cordas e membranas do corpo, prolongada para dentro

\footnotetext{
${ }^{16}$ Hobbes define o corpo como aquilo que não depende para sua existência do pensamento humano e que coincide com algum espaço.

Manuscrito - Rev. Int. Fil., Campinas, v. 34, n. 2, p. 579-616, jul.-dez. 2011.
} 
em direção ao cérebro e coração, causa ali uma resistência, ou contrapressão, ou esforço do coração para se transmitir, cujo esforço, porque para fora, parece ser de algum modo exterior" (Leviatã., I, cap. 1, p. 15).

É importante não confundir o objeto real com o objeto da representação. De fato, se o primeiro é determinado no estrito âmbito do movimento exterior, o segundo, por sua vez, é o resultado de uma consciência de exterioridade proveniente da projeção de qualidades e acidentes considerados, de forma ilusória ou enganosa pelo espírito, como sendo aquelas propriedades pertencentes à realidade exterior. Um passo além e veremos Hobbes afirmar que essas qualidades e acidentes das coisas que constituem nossas representações cognitivas não estão na verdade nas próprias coisas mas pertencem inteiramente à vida mental do sujeito epistêmico. Opera-se aqui, portanto, uma visível subsunção das qualidades secundárias e primárias $^{17}$ à vida cognitiva subjetiva, pois de acordo com o que diz Hobbes a seguir:

\footnotetext{
"Quaisquer acidentes ou qualidades que os nossos sentidos nos fazem pensar que existam no mundo, não estão lá, constituindo apenas aparências e aparições. As coisas que realmente estão no mundo, fora de nós, são os movimentos que causam essas aparências" (El., 2, 10, p. 56).
}

Todos os nossos pensamentos podem então ser definidos, diz Hobbes, como uma "representação ou aparência de alguma qualidade ou acidente de um corpo exterior a nós" (Leviatã, p. 15). Definir os pensamentos como representações cognitivas parece plenamente justificável no âmbito de um sistema de pensamento que combina componentes empíricos com componentes fenomênicos. Essa combinação revela uma démarche fundamental no interior do Leviatã quando Hobbes inscreve ali a seguinte proposição axiomática: “O homem não pode ter

${ }^{17}$ Natureza e distinção das qualidade primárias e secundárias.

Manuscrito - Rev. Int. Fil., Campinas, v. 34, n. 2, p. 579-616, jul.-dez. 2011. 
nenhum pensamento representando uma coisa que não esteja sujeita à sensação" (Leviatã, p. 29).

(d) Do Engano da Sensação e as Representações Imaginativas

No contexto da pura sensibilidade animal, porém, essas representações sensíveis - aqui traduzidas em pensamentos - estão todas invariavelmente circunscritas a enganos e ilusões. A razão disso é que todo pensamento representando algo está sujeito à sensação e a sensação é uma fonte originária de enganos e ilusões ocorridos na vida cognitiva dos indivíduos sencientes:

\begin{abstract}
"As coisas que realmente estão no mundo, fora de nós, são os movimentos que causam essas aparências. E esse é o maior engano da sensação, que também deve ser corrigido pela sensação, pois, assim como a sensação me diz, quando vejo diretamente um objeto, que a cor parece estar no objeto, assim também a sensação me diz, quando vejo por reflexão um objeto, que a cor não está nele" (El., 2, 10, p. 56).
\end{abstract}

O De Homine-óptico (isto é, a parte óptica do De Homine) tece importantes considerações relativas a esse engano originário da sensação no que diz respeito à percepção visual e às ilusões ópticas. De fato, Hobbes diz ali que "segundo uma instituição da natureza todo ser animado começa por julgar que essa imagem [uma luz, uma cor assim representada] é a visão da coisa mesma" ( $D H, 2,1, p .43)$. Observemos que Hobbes está ali usando novamente um modelo da percepção animal em geral para explicar o engano da sensação. Enganar-se ou iludir-se é pois algo inerente a todos os seres vivos animados. Em outras palavras, o engano originário da sensação é uma propriedade de todo indivíduo senciente que cai dentro do reino animal, gênero maior em que os sencientes humanos estão compreendidos como simples partes na relação com o todo. A falta de discernimento quanto à distinção entre objetos reais e objetos aparentes é originada pois naturalmente no interior da sensibilidade animal. Decorre disso que representações 
sensíveis cognitivas, isto é, "as representações das qualidades das coisas fora de nós" (El.,1, 8, p. 48), apresentarão ou reapresentarão interiormente os objetos externos como se eles fossem exteriores a um certo processo mental:

"Muito embora, a uma certa distancia, o próprio objeto real pareça confundido com a aparência que produz em nós, mesmo assim o objeto é uma coisa, e a imagem ou ilusão uma outra" (Leviatãa, p. 16).

Hobbes está abrindo caminho aqui para a instituição de um outro tipo de representação cognitiva. De fato, se a distinção no momento é entre objeto real e objeto imaginário, as representações sensíveis se transformam então em representações imaginativas. Essa transformação ocorre sem que o segundo termo implique a exclusão do primeiro, em nosso entendimento, porque em Hobbes a capacidade da imaginação é definida como um tipo específico de sensação, ou seja, ela é uma sensação enfraquecida ou debilitada, e isso devido ao estatuto da ausência de seu objeto. Com efeito, dada a ausência de um objeto epistêmico atual, representado anteriormente no contexto de um objeto presente responsável por aquela geração fenomênica de um objeto aparente, devemos pensar no momento num objeto aparente imaginário que é o objeto próprio das representações imaginativas cognitivas. As representações imaginativas são definidas por Hobbes da seguinte forma:

\footnotetext{
"Quanto à maneira pela qual se tem conhecimento de uma concepção passada, recorde-se a definição da imaginação onde dissemos que se trata de uma concepção que pouco a pouco declina, ou se vai tornando mais obscura. Uma concepção obscura é aquela que representa todo o objeto em conjunto, mas nenhuma das suas partes por si mesmas; e quanto mais ou menos partes forem representadas, assim se diz que a concepção ou representação é mais ou menos clara. Considerando então a concepção que, quando produzida pela sensação era clara e representava distintamente as partes do objeto, e quando nos vem novamente é obscura, achamos que nela falta algo que esperávamos e, por isso, a julgamos passada e enfraquecida" (El., 3, 7, p. 62).
}

Manuscrito - Rev. Int. Fil., Campinas, v. 34, n. 2, p. 579-616, jul.-dez. 2011. 
A partir daqui examinarei a teoria da representação visual de Hobbes, objetivando com isso uma melhor compreensão de sua teoria da representação cognitiva. Começo explicando como Hobbes concebe sua teoria física da luz para depois considerar a formação das representações visuais.

\section{As Representações Ópticas}

Do ponto de vista do conhecimento científico e filosófico o século XVII pode ser considerado uma época de rupturas e inovações. Noções como verdade, certeza e novidade eram frequentemente usadas pelos chamados inovadores (novatores) ${ }^{18} \mathrm{em}$ seu criticismo da tradição escolástica para ensejar o que entendiam ser um novo e verdadeiro sistema de pensamento fundamentado pelo rigor do raciocínio científico em detrimento do saber assentado na superstição ou na fé. Imprescindível à nova filosofia e à nova ciência, a separação entre razão e fé ou entre rąão natural e rąãa revelada traduzia-se em um relativo ${ }^{19}$ afastamento entre filosofia e teologia. Alinhado com esse ideário de

${ }^{18}$ De acordo com C. Leijenhorst "a separação em Hobbes entre razão e fé e sua distinção entre filosofia e teologia o situava num amplo movimento no século dezessete", de forma que "como muitos dos novatores Hobbes sente que tinha de defender a autonomia da filosofia, a libertas philosophandi, contra as tendências imperialistas dos teólogos" (cf. Leijenhorst 2002, p. 27). Já P-F. Moreau diz que “o mundo que se inaugura então é um mundo em crise: pois se vê ele mesmo como que lutando por uma nova forma de pensamento contra uma outra que ainda não morreu; combatendo a tradição ... [e] edificando os sistemas inovadores (systèmes novateurs) ... [Hobbes] está perfilado inegavelmente no campo dos nouveaux philosophes da idade clássica, daqueles que querem, cada um ao seu modo, tirar do conjunto do pensamento as conseqüências dessa mudança radical” (Moreau 1989, pp. 27-28).

19 A autonomia da filosofia em relação à teologia varia nessa época de acordo com as convicções religiosas de cada pensador. Nesse sentido, Kepler se mostra intimamente atrelado à religião para negar a infinitude do mundo enquanto Hobbes afirma a radical separação entre o Estado e a igreja, preconizando assim a exclusão das igrejas do exercício do poder político.

Manuscrito - Rev. Int. Fil., Campinas, v. 34, n. 2, p. 579-616, jul.-dez. 2011. 
filósofos e cientistas que acreditavam na necessidade de uma profunda reformulação de ideias para prover a geração de uma nova concepção de mundo, Hobbes estava convencido que antes de Galileu e Harvey "não havia nenhuma certez̧a na Física" e que depois deles "Kepler, Gassendi e Mersenne promoveram de forma extraordinária a Astronomia e a Física universais" (De Corpore, ep. ded. pp. 29-30).

Postulados metafísicos associados a reflexões pertencentes à esfera da ciência óptica era um recurso bastante usado pelos inovadores para pensar o novo mundo e as novas descobertas científicas. De acordo com o que diz A. Koyré em Do mundo fechado ao universo infinito, Kepler recorre a raz̃ós metafísicas e à óptica para negar a doutrina da infinitude do mundo porque em se tratando do mundo que nós vemos, segue que "a Astronomia está estreitamente relacionada com a visão, ou seja, com a óptica, [e] não pode admitir coisas que contradigam as leis da óptica". ${ }^{20}$ Penso que não será sem propósito observarmos que a primeira obra de Hobbes, isto é, o Curto Tratado, e a sua última obra, isto é, o De Homine, tratam de questões relativas à óptica. Antes de refletirmos sobre a teoria óptica de Hobbes, porém, parece oportuno considerarmos brevemente certos posicionamentos relacionados a estudos ópticos precedentes e contemporâneos aos estudos ópticos do filósofo inglês.

\section{Da óptica antiga à óptica moderna}

Em O Olhar, o Ser e a Aparência na óptica da antiguidade, G. Simon observa que a óptica antiga visava explicar menos as causas físicas da luz que a visibilidade, de forma que os estudos ópticos da antiguidade estariam assentados "na hipótese da emissão do raio visual a partir do olho". ${ }^{21}$ Ele chega a essa conclusão através da leitura de textos relativos ao fenômeno óptico da época, os quais permitem a constatação que

\footnotetext{
${ }^{20}$ Koyré (2001, pp. 63-66).

21 Simon (1988, p. 16).
}

Manuscrito - Rev. Int. Fil., Campinas, v. 34, n. 2, p. 579-616, jul.-dez. 2011. 
nesse período o objeto de estudo da óptica é o conceito de raio visual ao invés do conceito de raio luminoso. Simon destaca a tendência dos modernos em interpretar a óptica antiga na perspectiva do conceito de raio luminoso, desconsiderando dessa forma a fundamental distinção feita pelos antigos entre cones visuais e cones de lu\%. Por exemplo, aprendemos com Euclides (300 a.C.), cuja obra é sinal de demarcação da óptica antiga, que não se pode separar o olhar da faculdade que julga e que conhece por que "a figura circunscrita pelos raios visuais é um cone que tem seu cume no olho e sua base nos limites daquilo que é visto". ${ }^{22}$ A redução da luz e das cores ao cálculo que estabelece a forma e os contornos do visivel conduz a óptica antiga em seu conjunto para uma espécie de geometria do olhar. Evidencia-se pois, conclui Simon, que na teoria da emissão da luz dos antigos a emissão material dos feixes luminosos é compreendida nos termos de uma abstração geométrica:

\footnotetext{
"[A óptica antiga] foi em primeiro lugar uma analitica do olhar. Invenção capital, metodicamente explorada por Euclides, ela imagina fazer corresponder... a um componente (élément) do visível um componente da vista $(v u e)$. O vínculo entre um e outro é o raio visual: a retidão (rectitude) que lhe atribuímos permite transformar o problema imensamente complexo da visão (o que é ver e como vemos?) em uma investigação propriamente geométrica: como percebemos as direções, as distancias, as grandezas, as formas, os movimentos?"23
}

Esse modelo óptico que explica a luz através da noção de visibilidade, ao invés de explicá-la através de suas propriedades de propagação, começou a sofrer alterações significativas com os estudos ópticos de medievos como Al-hazen (965-1040) no século X e Vitelo (1220-1278) no século XIII. Al-hazen introduz no campo da óptica a teoria da recepção pelo olho dos raios de luz bem como formula as bases da teoria da propagação da luz que dominará a óptica moderna. Posteriormente Vitelo deu continuidade aos escritos ópticos de Al-

\footnotetext{
22 Euclides, Óptica. In: Simon (1988), op. cit., p. 21.

${ }^{23}$ Simon (1988), op. cit., p. 187.

Manuscrito - Rev. Int. Fil., Campinas, v. 34, n. 2, p. 579-616, jul.-dez. 2011.
} 
hazen, desenvolvendo, além disso, importantes estudos na área de perspectiva óptica, onde elaborou uma das primeiras análises sobre a percepção do espaço. Mas Vitelo ainda preservava um tipo de metafísica neoplatônica da luz em que concebia a realidade material como reflexo de uma forma irradiante de luz que se identificava com Deus. Apesar das descobertas dos medievais no campo da óptica, portanto, essa permanecia ainda definida como ciência da luz e da visão e o vidente e o visivel unificados como os dois lados de uma mesma moeda. ${ }^{24}$

A ideia da teoria óptica como física da luz surge com Kepler (1571-1630) no século XVII a partir da descoberta da "formação de uma imagem real sobre a retina, produzida pela convergência do cristalino concebido como o análogo de uma lente". ${ }^{25}$ A partir dessa descoberta o olho passa a receber o estatuto de dispositivo óptico, de forma que a ideia do olho como um órgão sensorial reduzido à sensibilidade, isto é, à sensibilidade qua projeção material e psíquica, perde gradativamente sua força argumentativa.

O raio de luz é doravante concebido como uma realidade e não mais como uma projeção do visível: - A teoria física da luz dos modernos tem a partir de então como objeto a propagação dos raios luminosos, o que implica um afastamento determinante da ideia de raio visual remanescente de estudos ópticos antigos. O que não significa que a ideia de visibilidade seja descartada definitivamente ${ }^{26}$ mas tãosomente que a partir das novas descobertas a ciência óptica passa por um processo de bifurcação que terminará por dividi-la em teoria da luz e teoria da visão.

\footnotetext{
24 Cf. Prins (1987).

${ }^{25}$ Simon (1988), op. cit., pp. 12-12.

26 Os estudos ópticos de Descartes podem ser sintetizados, conforme diz M. Fichant, na idéia de uma "geometria do olhar". Ver também a analise que M. Ponty faz de Descartes em "O olho e o espírito", em especial a concepção de "pensamento visual" que M. Ponty atribui como sendo um modelo óptico cartesiano.
}

Manuscrito - Rev. Int. Fil., Campinas, v. 34, n. 2, p. 579-616, jul.-dez. 2011. 
Os estudos ópticos de filósofos como Hobbes e Descartes seguem rigorosamente essa nova classificação que estabelecerá os contornos do campo de estudo da óptica renascentista. Como o meu principal interesse aqui é abordar a teoria da visão de Hobbes para compreender como ele opera a construção do seu conceito de representação visual, examinarei a seguir, de forma en passant, a parte física da sua óptica, para depois considerar a sua teoria da visão e sua teoria da representação visual.

\section{Hobbes e as causas físicas da luz.}

A teoria da intromissão da luz de Al-Hazen, isto é, a ideia que vemos através de raios de luz que entram nos olhos a partir do exterior, substitui gradativamente a teoria da emissão da luz dos antigos, isto é, a ideia que vemos através de raios visuais emitidos pelo olho. Vitelo continua os estudos de Al-Hazen e acrescenta que o raio de luz deve ser definido como um feixe de linhas matemáticas. ${ }^{27}$ A explicação física da luz recebe com Vitelo um "tratamento puramente geométrico" de forma que o fenômeno óptico passa a ser explicado em termos de "pontos e linhas". ${ }^{28}$ Prins sugere que os estudos desenvolvidos pelos ópticos medievais reduzem a óptica à geometria de forma que a natureza da luz é por eles formulada a partir de um tratamento puramente geométrico de problemas físicos justificado pelo conceito de raio de luz. ${ }^{29}$ Em resumo, a forma geométrica como os antigos explicavam a visão através da noção de raio visual sofre uma readequação com os medievais de forma a conduzir a uma explicação física da luz justificada pela geometrização do raio de luz.

A teoria física da luz de Hobbes parece compatível com a teoria da intromissão da luz dos ópticos medievais. Hobbes utiliza, por

\footnotetext{
${ }^{27}$ Prins (1987), op. cit., p. 296.

28 idem.

29 idem.
}

Manuscrito - Rev. Int. Fil., Campinas, v. 34, n. 2, p. 579-616, jul.-dez. 2011. 
exemplo, o termo lux para se referir à fonte original de luz que irradia de um corpo luminoso antes de se dirigir para o centro do olho. Lux, dessa forma, é distinto de lumen, visto que esse último termo se refere não à luz original mas à luz refletida, isto é, à luz como fantasma, que pertence à sua teoria da visão. ${ }^{30} \mathrm{~A}$ objetividade da causa física da luz (lux $x$ é diferente em Hobbes da subjetividade da qualidade sensível (lumen), que surge como uma reação no interior do dispositivo óptico em decorrência de estímulos nervosos no cérebro e no coração. A óptica hobbesiana remete dessa forma a uma teoria da intromissão da luz ao definir as causas físicas da luz pelo termo lux e a uma teoria da emissão da luz compreendida como lumen ou fantasma. ${ }^{31}$ A primeira explicação do fenômeno óptico na terceira seção do Curto Tratado

${ }^{30}$ É de se observar que já no CurtoTratado Hobbes se refere ao termo lux como luz primitiva e ao termo lumen como luz derivada. $\mathrm{Na}$ medida que "por luz primitiva se entende lux [e] por [luz] derivada lumen" surge então como corolário que assim como "a luz primitiva e a cor estão para os corpos luminosos ou coloridos assim a luz derivada e a cor estão para as espécies".

31 Segundo Prins a óptica de Hobbes não é geométrica uma vez que ela está determinada causalmente pelo movimento. A óptica de Hobbes estaria, ainda segundo Prins, situada no plano da física matemática. Zarka sugere, ao contrário, que ela é geométrica e remete ao começo do De Homine onde Hobbes diz que a óptica é uma ciência demonstrativa da mesma forma que a geometria, de modo que, continua Zarka, é importante não confundir "os movimentos da matéria que produzem em nós a representação da luz ou do calor com as qualidades sensíveis". Em nossa opinião, são dois diferentes enfoques da teoria óptica de Hobbes que não precisam ser necessariamente excludentes. Sugiro que há em Hobbes a compatibilidade entre uma mecanização da luz e uma geometrização do olhar, o que podemos observar, por exemplo, através da passagem em Hobbes das razões físicas da luz para o ato da construção geométrica do visível, ou ainda pela comparação do termo lux com o termo lumen.

Manuscrito - Rev. Int. Fil., Campinas, v. 34, n. 2, p. 579-616, jul.-dez. 2011. 
evidencia a objetividade da causa da luz amparada na explicação clássica da emissão da luz pelas espécies através de um medium:

\begin{abstract}
"Luz, cor, calor e outros objetos próprios da sensação ... nada mais são do que as diferentes ações das coisas exteriores sobre os espíritos animais, pelos diferentes órgãos. Pois se a luz e o calor fossem qualidades inerentes em ato às espécies, e não diferentes modos de ação porque as espécies entram por todos os órgãos para ir aos espíritos se deveria ver o calor e sentir a luz, o que é contrário à experiência" (CTr., p. 45).
\end{abstract}

O Curto Tratado apresenta dessa forma uma explicação da teoria mediúnica da luz apoiada no conceito de species (especies sensíveis). O fundamento lógico dessa explicação, conforme estabelecido por Hobbes na terceira seção do Curto Tratado, consiste em que a causa eficiente está do lado do objeto e não do lado do sujeito. De fato, a terceira seção do Curto Tratado esclarece que "o objeto é a causa eficiente ou agente do desejo e os espíritos animais o paciente" (CTr., p. 53). Uma vez estabelecido que o princípio de causalidade é da ordem do objeto e não da ordem do sujeito, segue como corolário que a natureza mediúnica da luz é compatível com a teoria da emissão das species: "Todo agente que age sobre um paciente à distância o toca seja pelo Medium, seja por alguma coisa que sai dele mesmo, a qual será denominada Species" (CTr., p. 25). Essa concepção começa porém a sofrer mudanças a partir do Tractatus Opticus I onde Hobbes afirma que "se não houvesse visão não haveria nada que chamaríamos de luz" ( $T$. op. I, O. L., V, p. 220). A aparição da luz e das cores é doravante um fenômeno subjetivo e situa-se em claro contraste com a tese objetivista da emissão da luz pelas espécies do Curto Tratado. Se no plano da origem da luz a teoria da luz de Hobbes, devido à inserção das teses do Tractatus Opticus I, passa a indicar um movimento que articula a ação do meio a partir da fonte luminosa, esse movimento, concebido como propagação da luz a partir do meio, vem a ser luz somente quando há um sentimento da luz em nós, o qual é definido como visão.

Manuscrito - Rev. Int. Fil., Campinas, v. 34, n. 2, p. 579-616, jul.-dez. 2011. 
Por outras palavras, lux e lumen são explicados doravante de forma subjetiva. A conclusão das teses ópticas no pensamento óptico da maturidade ${ }^{32}$ de Hobbes mostra pois que a ação física da luz não basta para explicar todas as modalidades da visão. A passagem das causas físicas da luz para a explicação da visão através da constituição do conceito de representação visual é o que pretendemos examinar no próximo item.

\section{A FORMAÇÃO DAS REPRESENTAÇÕES VISUAIS}

Estabelecida a tese que a ação física da luz é insuficiente para produzir a visão, a teoria óptica hobbesiana remete a um complexo sistema psíquico fisiológico para adequar a teoria da luz à teoria da visão:

“A ação de um objeto luminoso, quando propagada para o fundo do olho e consequentemente para o cérebro, é a causa da reação pela qual um movimento é transmitido para fora do cérebro, através do olho, na direção dos objetos externos. O último movimento, contudo, é experimentado não como movimento mas como fantasia ou imagem... de algum corpo luminoso. Essa fantasia se chama iluminação ou luz" (De Mundo, IX, p. 102).

Doravante a luz e a cor são consideradas "não como emanações do objeto mas como fantasmas de nosso mundo interior" (De Homine, II, p. 43). É de se observar que a idéia de fantasma como recurso para explicar o fenômeno visual faz parte da literatura óptica dos medievais e dos renascentistas. Vitelo, por exemplo, recorre à idéia de fantasma para explicar a ilusão visual e podemos constatar, além disso, que o Optical Thesaurus de 1572 traz uma identificação entre fantasma e imagem refratária. ${ }^{33}$ Outra observação que nos parece relevante é que se na Critica do 'De Mundo' Hobbes se refere à luz como fantasia,

\footnotetext{
32 Isto é, no Tractatus Opticus I e II, mas também no De Homine.

33 Cf. Prins (1987), op. cit., pp. 303-304.
}

Manuscrito - Rev. Int. Fil., Campinas, v. 34, n. 2, p. 579-616, jul.-dez. 2011. 
no De Homine ele se refere à luz como fantasma. Seria devido ao fato que na Critica do 'De Mundo' ele em muitos aspectos se mostra disposto a seguir Aristóteles para quem a raiz etimológica da palavra fantasia é dada pelo vocábulo luæ? De fato, Dherbey sugere que a identificação de fantasia e luz em Aristóteles serve para dissipar o erro de não se diferenciar a sensação da imaginação: - "A confusão feita por Protágoras entre sentir e imaginar se explica se atentamos à etimologia de phantasia que, nos diz Aristóteles, vem de phaos, a luz". ${ }^{34}$

Diferentemente de Aristóteles, conforme podemos observar nos escritos ópticos do De Homine, Hobbes não está preocupado em identificar fantasia e Lu₹ para separar sensação e imaginação e sim identificar fantasma e luz para separar a imagem visual do objeto da visão. Com efeito, após definir a luz no De Homine como fantasma de nosso mundo interior, Hobbes pode operar uma distinção fundamental entre o que é da ordem da representação visual e o que é da ordem da própria coisa:

\footnotetext{
"Uma luz, uma cor assim figurada [isto é, representada], isso se chama uma imagem. E, segundo uma instituição da natureza, todo ser animado começa por julgar que essa imagem é a visão da coisa mesma... [Sendo que] mesmo os homens... confundem a imagem com o próprio objeto" (De Homine, II, p. 43).
}

Lembremos que essa idéia de uma separação radical entre o fenômeno visual e a própria coisa conforme estabelecida por Hobbes no De Homine de 1658 remonta ao ano de 1649 quando ele escreve o tratado óptico A Minute or First Draught of the Optiques. Essa constatação se deve ao fato de que a parte óptica do De Homine corresponde quase que integralmente à segunda parte do First Dranght, parte essa que Hobbes dedica ao estudo da visão. ${ }^{35}$ A construção óptica da representação

${ }^{34}$ Dherbey (1983), op. cit., p. 61.

$35 \mathrm{O}$ motivo pelo qual Hobbes deixou a primeira parte do First Dranght, isto é, a teoria da luz, fora do De Homine ainda hoje é um mistério para os que

Manuscrito - Rev. Int. Fil., Campinas, v. 34, n. 2, p. 579-616, jul.-dez. 2011. 
em Hobbes começa a ser delineada enfim através da justaposição de uma fundamental diferenciação entre o que é da ordem do aparecer e o que é da ordem da realidade.

Tendo isso em mente podemos constatar que a imagem é construída visualmente em nosso cérebro na medida em que somos afetados por um objeto externo e que quando essa imagem é projetada de dentro para fora por reação dos estímulos nervosos centrais temos a ilusão que o que vemos é a própria coisa. Constata-se pois que as teses ópticas de Hobbes se posicionam de forma antagônica com a óptica antiga uma vez que "aquilo que um Antigo vê num espelho é a própria coisa". ${ }^{36} \mathrm{Em}$ A teoria aristotélica da visão Cappelletti diz, por exemplo, que é importante sublinhar que existe em Aristóteles uma teoria realista da sensação visual segundo a qual o sujeito capta qualidades que se encontram verdadeira e realmente no objeto, de forma que os "erros e ilusões se referem aos sensíveis comuns (distancia, magnitude, etc.) e não são na realidade erros da vista mas do entendimento". ${ }^{37}$

Explicar como se formam as imagens visuais a partir de uma separação radical entre o que é da ordem do fenômeno e o que é da

estudam sua teoria óptica. Seria porque ao tratar do homem (De Homine) ele pensava que as razões físicas da luz podem ser subsumidas na noção de luz como fantasma de nosso mundo interior? O fato é que dois anos depois do First Dranght Hobbes escreve no inicio do Leviathan (1651) — sua obra política maior - que embora "o próprio objeto real pareça confundido com a aparência que produz em nós, mesmo assim o objeto é uma coisa, e a imagem ou ilusão uma outra". A critica à doutrina óptica escolástica da emissão da luz por species visível é o recurso que Hobbes usa no Leviathan para sustentar a diferença entre percepção visual e a realidade. Aristóteles criticou Protágoras por não diferenciar sensação e imaginação. O primeiro capitulo do Leviathan é dedicado ao exame da sensação e o segundo capitulo ao exame da imaginação. Mas ao contrário de Aristóteles, embora Hobbes num primeiro momento diferencie sensação e imaginação, num segundo momento ocorre a subsunção da imaginação à sensação, isto pelo fato que para ele "a imaginação é uma sensação diminuída".

${ }^{36}$ Simon (1988), op. cit., p. 197. O itálico é meu.

${ }^{37}$ Cappelletti (1977, p. 91).

Manuscrito - Rev. Int. Fil., Campinas, v. 34, n. 2, p. 579-616, jul.-dez. 2011. 
ordem das coisas é o tema do capitulo primeiro da parte óptica do $D e$ Homine. De fato, a noção de representação visual orienta ali o processo de formação das imagens. A percepção visual da irradiação do corpo luminoso é enviada através do dispositivo óptico para o sistema nervoso central provocando ali uma reação para fora que consistirá nas aparições ou fantasmas de nosso mundo interior. O que segue disso tudo é uma síntese dos múltiplos pontos de visão que irão constituir a imagem visual do objeto segundo uma correspondência ordenada:

\begin{abstract}
"Uma visão [isto é, uma imagem visual] distinta e figurada ocorre quando a luz ou a cor forma uma figura cujas partes tem por origem as partes do objeto, e lhes corresponde uma à uma na ordem. Uma luz, uma cor assim figurada [isto é, representada], isso se chama uma imagem" (De Homine, II, p. 43).
\end{abstract}

O estatuto representacional da visão, da forma apresentada nessa passagem no De Homine óptico, parece plenamente compatível com o que Hobbes escreve na Crítica do 'De Mundo' nos termos de uma superfície aparente imaginária: "A área aparente do sol ou de qualquer outro objeto não é inerente no próprio objeto mas é meramente imaginária" (De Mundo, III, p. 40). A superfície aparente imaginária é constituída ponto por ponto a partir das informações visuais que temos das partes do objeto luminoso. Ora, no De Homine Hobbes enuncia justamente que a configuração dos pontos de visão justapostos numa linha reta no centro retinal do aparelho óptico se chama linha de visão:

\footnotetext{
"Cada ponto visto é situado sobre uma linha reta que passa primeiramente pelo centro da retina, depois por um ponto de sua superfície... [sendo que] essa linha reta chamar-se-á linha de visão" (De Homine, II, p. 44).
}

O lugar aparente das imagens que temos dos objetos, a saber, "a forma como aparecem na visão direta", é então explicado no capítulo terceiro do De Homine a partir da mencionada noção de linha visual:

Manuscrito - Rev. Int. Fil., Campinas, v. 34, n. 2, p. 579-616, jul.-dez. 2011. 
"Por conseguinte, se damos a distância aparente de um objeto (colocado em linha reta), [bem como] a sua grandeza aparente e a sua figura aparente, [segue que] o seu lugar aparente é igualmente dado" (De Homine, III, p. 59).

A localização dos objetos na representação é dessa forma estabelecida na linha de visão, isto é, na linha reta, pela determinação do lugar e da distância real dos objetos a partir de seu lugar e de sua distância aparente. Sobre essa questão Zarka esclarece que em Hobbes "a constituição visual da representação governa o problema da determinação da distância e do lugar real do objeto a partir de seu lugar aparente". ${ }^{38}$ O lugar e a distância real são dessa forma reduzidos ao que aparece. A imagem visual, formada a partir da linha de visão, é percebida pelo indivíduo receptor "como se" 39 fosse a própria coisa. Nos Elementos da lei, lembremos, Hobbes esclarece essa questão da seguinte forma:

\footnotetext{
"Por isso, segue-se também que quaisquer acidentes ou qualidades que os nossos sentidos nos fazem pensar que existam no mundo, não estão lá, constituindo apenas aparências e aparições. As coisas que realmente estão no mundo, fora de nós, são os movimentos que causam essas aparências" (El. Lei., p. 56).
}

${ }^{38}$ Cf. Zarka (1987), op. cit., p. 138.

${ }^{39}$ É de se observar, porém, que o componente racional não está presente nesse estágio de argumentação. Em outras palavras, as correções efetuadas pelo raciocínio - por exemplo, aquelas relativas às ilusões ópticas — remetem a um plano objetivo que não interessa a Hobbes nesse estágio do argumento. (A critica de Hobbes das Species invisiveis dos escolásticos, por exemplo, é uma critica da razão dirigida a todos aqueles que postulam raciocínios equivocados por não conseguirem decifrar os enganos da visão natural a partir da distinção entre a dimensão do aparecer e a dimensão da realidade ou ainda a partir da distinção entre o que é da ordem da subjetividade e o que é da ordem da objetividade.) O que realmente importa aqui é que "por natureza" a luz e a cor são compreendidos como fantasmas puramente subjetivos que determinam o modo como vemos as coisas.

Manuscrito - Rev. Int. Fil., Campinas, v. 34, n. 2, p. 579-616, jul.-dez. 2011. 
Existindo no mundo apenas aparências e aparições, a realidade se encontra subsumida nas representacõoes visuais. A forma como vemos as coisas é então a forma como o visivel se manifesta. Tudo isso constitui a instigante e ainda hoje pouco explorada teoria óptica de Hobbes. A relação do desejo com as cores ou a metafórica comparação da filosofia política com um telescópio (telescopii), conforme constatamos no Leviathan em latim, são algumas das questões que surgem de forma surpreendente quando examinamos o mundo predominantemente visual de Hobbes.

\section{REFERÊNCIAS BIBLIOGRÁFICAS}

\section{Obras de Hobbes}

Court traité des premiers principes, edição bilíngüe inglês-francês, sob os cuidados de J. Bernhardt, Paris, P.U.F., 1988.

De Cive ou les fondements de la politique (tradução de S. Sorbière), Paris, Éditions Sirey, 1981.

De Homine, tradução para o francês de Paul-Marie Maurin, Paris, Librairie Scientifique et Technique, 1974.

De Homine e De Cive, editado por B. Gert com o título Man and Citizen, Cambridge, Haackett Publishing Company, 1991.

De la Liberté et de la Nécessité, tradução de F. Lessay, Paris, Vrin, 1993.

De la Nature Humaine, traduzido do inglês para o francês pelo Barão d'Hilbach, comentário de E. Roux, Saint-Amand-Montrond, Actes Sud, 1997.

Manuscrito - Rev. Int. Fil., Campinas, v. 34, n. 2, p. 579-616, jul.-dez. 2011. 
Do Cidadão, tradução de Renato Janine Ribeiro. São Paulo, Martins Fontes, 1993.

Exame do 'De Mundo' de thomas White, tradução inglesa do Latim feita por Harold Whitmore Jones cujo título é Thomas White's De Mundo examined, editado por Bradford University (1976).

Leviatã, edição Martins Fontes, São Paulo, 2003 (traduzido para o português por João Paulo Monteiro e Maria Beatriz Nizza da Silva).

Leviathan, editado com uma introdução de C. B. Macpherson, London, Penguin Books, 1985.

Natureza Humana (primeira parte dos Elementos da Lei), editado pela Imprensa Nacional - Casa da Moeda, Lisboa 1983.

Optical Treatise (Tratado Óptico I), tradução de G. M. Ross, texto extraído do seguinte site: http:// www. Philosophy.leeds.ac.uk

The English Works of Thomas Hobbes, editado por W. Molesworth. London: 1839 (edição eletrônica em CD-ROM - Intelex Corporation, 1993).

Tratado sobre el cuerpo, na tradução castelhana do De Corpore realizada por J.R. Feo, Madrid, Editorial Trotta, 2000. 


\section{Estudos sobre Hobbes}

ANGOULVENT, A.-L. Hobbes on la crise de l'État baroque. Paris: P.U.F., 1992.

BERNHARDT, J. Hobbes. Paris: PUF, 1989.

BRANDT, F. Thomas Hobbes's mechanical conception of nature. London: Librairie Hachette, 1928.

CAPPELLETTI, A. J. La teoria aristotélica de la visión. Caracas: Soc. Venezolana de Ciencias Humanas, 1977.

DERBHEY, G. R. Les choses mêmes: la pensée du reel chez. Aristote. Lausanne: Editions l'Age d'Homme, 1983.

FICHANT, M. Science et métaphysique dans Descartes et. Leibniz. Paris: P.U.F., 1998.

GOLDSMITH, M.M. Hobbes's Science of Politics. New York: Columbia University Press, 1966.

GRUNDSTEIN, N. The Future of Prudence: Pure Strategy and Aristotelian and Hobbesian Strategists. Ohio: A Zeus Book, 1983.

KOYRÉ, A. Do Mundo Fechado ao Universo Infinito. Rio de Janeiro: Forense Universitária, 2001.

LEIJENHORST, C. The Mechanisation of Aristotelianism: the late Aristotelian setting of Thomas Hobbes' Natural Philosophy. Boston: Brill, 2002.

LEIVAS, C.R.C. "Situação de Conflito e Condição de Obrigação em Hobbes”. Disputatio: Revista Internacional de Filosofia Analítica, n. 9, pp. 19-35, 2000.

MALHERBE, M. Thomas Hobbes ou L'oeuvre de la Raison. Paris: Vrin, 2000.

Manuscrito - Rev. Int. Fil., Campinas, v. 34, n. 2, p. 579-616, jul.-dez. 2011. 
MARTINICH, A. P. A Hobbes Dictionary. Cambridge: Blackwell Publishers, 1996.

MINTZ, S. The Hunting of Leviathan. Cambridge: CUP, 1970.

MOREAU, P-F. Hobbes: Philosophie, science, religion. Paris: P.U.F, 1989.

PÉCHARMAN, M. "Le vocabulaire de l'être dans la philosophie première: ens, esse, essential". In: Y.C. Zarka (org) (1992), pp. 31-59.

PETERS, R. Hobbes. London: Peregrine Books, 1967.

PONTY, M. L'oeil et L'esprit. Paris: Gallimard, 1985.

PRINS, J. "Kepler, Hobbes and medieval optics". Philosophia Naturalis, 24, pp. 287-310, 1987.

ROGERS G. A. J. and RYAN, A. (eds.), Perspectives on Thomas Hobbes. Oxford: Clarendon Press, 1998.

SIMON, G. Le Regard, L'Être et L'Apparence dans L'Optique de L'Antiquité. Paris: Éditions du Seuil, 1988.

SORELL, T. Hobbes. London and New York: Routledge, 1991.

SPRAGENS, T.A. The Politics of Motion. London: The Trinity Press, 1973.

TUCK, R. Hobbes. Oxford: Oxford University Press, 1989.

ZARKA, Y.C. La Décision Métaphysique de Hobbes. Paris: Vrin, 1987.

(org.) Hobbes et son vocabulaire. Paris: Vrin, 1992a.

"Vision et désir chez Hobbes". Recherches sur le XVII' siecle, n 8, pp. 127-142, 1986.

"Le vocabulaire de l'apparaitre". In: Y.C. Zarka (org) (1992)b, pp. 13-29. 